
\title{
ПОВЫШЕНИЕ КАЧЕСТВА МЕНЕДЖМЕНТА В НАУКОЕМКОМ БИЗНЕСЕ ЗА СЧЕТ ИНСТРУМЕНТОВ ВНУТРЕННЕГО КОНТРОЛЯ
}

\section{IMPROVING THE QUALITY \\ OF MANAGEMENT IN THE HIGH \\ TECHNOLOGY BUSINESS AT THE EXPENSE \\ OF INTERNAL CONTROL TOOLS \\ G. Butko \\ M. Menshikova \\ E. Tikhomirov \\ P. Porotnikov}

Summary: Background. The existing processes of economic instability have caused a number of urgent problems, among which, special attention is drawn to the quality of management in the knowledge-intensive business in Russia. Low economic indicators against the background of significant risks have a significant impact on the development of this sector. Formation of an effective high-quality enterprise management system will ensure stable dynamics of its development.

Methods. To ensure the pragmatics of any special term, it is not enough to define "quality", "competition" and "competitiveness" in the traditional sense. It requires a kind of explication that would establish, even at the most General level, the relationship of this concept and its components with other categories of the subject area.

Results. The quality system tries to reduce the risk by eliminating additional uncertainties associated with competitors ' actions. The inadequacy of any social system's response is expressed in its actions aimed at protecting its own capabilities and neutralizing the actions of competitors. Neutralizing competitors increases the system's ability to manage the market situation.

Conclusion. The quality management system at industrial, including science-intensive enterprises, should be continuously improved. The developed guidelines for the assessment and control of the system make it possible to improve the efficiency of management and the effectiveness of activities. The current situation, which confirms a high degree of anthropogenic load, can be solved by taking into account the innovative component.

Keywords: quality of management; accounting policy; licensed accounting automated program; high technology business; efficiency of internal control system.
Бутко Галина Павловна

Д.э.н., профессор, ГБОУ ВО «Уральский государственный лесотехнический университет»; ГБОУ ВО «Уральский государственный экономический университет», г. Екатеринбург, gpbutko@mail.ru

Меньшикова Маргарита Аркадьевна Д.э.н., профессор, ГБОУ ВО Московской области «Технологический Университет имени дважды героя Советского Союза, летчика-космонавта А.А. Леонова»,

г. Королев

Ivn-3@yandex.ru

Тихомиров Евгений Александрович

К.э.Н., доцент, ГБОУ ВО «Мытищинский филиал Московского государственного технического университета им. Н.Э. Баумана»

tihomirov@mgul.ac.ru

Поротников Павел Анатольевич

К.э.н., старший преподаватель, ФГКОУ ВО «Уральский юридический институт Министерства внутренних дел

Российской Федерачии», г. Екатеринбург

pekin-auto@mail.ru

Аннотация: Состояние вопроса. В современной экономической ситуации реально действующие процессы экономической нестабильности обусловили ряд актуальных проблем, среди которых, особое внимание привлекает качество менеджмента в наукоемком бизнесе России. Существенное влияние на развитие этого сектора оказывают невысокие экономические показатели на фоне значимых рисков. Формирование эффективной качественной системы управления предприятием, обеспечит устойчивую динамику его развития. Материал и методы исследования. Для обеспечения прагматики любого специального термина недостаточно определения «качество», «конкуренция» и «конкурентоспособность» В традиционном понимании. Требуется своего рода экспликация, которая бы устанавливала, пусть на самом общем уровне, взаимосвязь самого этого понятия и его компонентов с другими категориями предметной области.

Результаты исследования и их обсуждение. Система качества пытается уменьшить вероятность риска путём исключения дополнительных неопределённостей, связанных с действиями конкурентов. Неадекватность реакции любой социальной системы выражается в её действиях, направленных на защиту своих возможностей и нейтрализацию действий конкурентов. Нейтрализация конкурентов повышает возможность системы управлять ситуацией на рынке. Заключение. Система менеджмента качества на промышленных и в том числе наукоемких предприятиях должна непрерывно совершенствоваться. Разработанные методические рекомендации по оценке и контролю системы позволяют повысить эффективность управления и результативность деятельности. Современная ситуация, подтверждающая высокую степень антропогенной нагрузки, может быть решена на основе учета инновационной составляющей.

Ключевые слова: качество менеджмента; учетная политика; лицензионная бухгалтерская автоматизированная программа; наукоемкий бизнес; эффективность системы внутреннего контроля. 


\section{Введение}

B современной экономической ситуации реально действующие процессы экономической нестабильности обусловили ряд актуальных проблем, среди которых, особое внимание привлекает качество менеджмента в наукоемком бизнесе России. Существенное влияние на развитие этого сектора оказывают невысокие экономические показатели на фоне значимых рисков. Формирование эффективной качественной системы управления предприятием, обеспечит устойчивую динамику его развития.

Как правило, в настоящее время в качестве основной причины возникновения ситуаций, связанных с риском на наукоемких предприятиях, выделяют не только неопределенность финансово-хозяйственной деятельности, которая напрямую осуществляется из средств федерального бюджета, но и неустойчивость конъюнктуры рынка.

Довольно часто наукоемкие предприятия работают по госзаказу. Оперативность в реализации запланированных разработок, а также наращивание потенциала и повышения качества в сфере НИОКР, мотивированы в первую очередь, затруднительной обстановкой в ходе исполнения государственного заказа прошедших лет.

В последние годы была проведена активная работа по поддержанию положительной динамики развития наукоемкого сектора и в первую очередь, в ракетнокосмической отрасли, о чем свидетельствует ряд значительных изменений по осуществлению деятельности в рамках ГОЗ. В первую очередь, законодательство претерпело изменения в порядке исполнения процессов договорной работы, планирования и бюджетирования. Особое внимание уделено концепции регулировании цен на товары и НИОКР.

Современный этап развития в значительной мере зависит от того, насколько сильна фирма и адаптирована к изменениям внешней среды, в какой степени ее структуры устойчивы, восприимчивы к инновациям. Потребность в инновациях, способность к инновациям стала императивным требованием к обеспечению высокого качества.

Важно подчеркнуть, что под требования качества попадают не только товары и изделия, производимые предприятиями космической промышленности, а также увеличение продуктивности труда. В первую очередь, установка на высокую эффективность качества теперь распространяется на научно-технические услуги, работы и НИОКР, которые представлены в виде этапов выполнения определенных бизнес-процессов.

\section{Шель исслеАования}

Разработка инструментов по интегрированию системы внутреннего контроля в систему корпоративного менеджмента наукоемкого бизнеса с целью повышения его качества.

\section{Материал и методы исследования}

Для обеспечения прагматики любого специального термина недостаточно определения «качество», «конкуренция» и «конкурентоспособность» В традиционном понимании. Требуется своего рода экспликация, которая бы устанавливала, пусть на самом общем уровне, взаимосвязь самого этого понятия и его компонентов с другими категориями предметной области. Известно определение качества с позиции конкуренции, приведенное в Законе РФ «О конкуренции». Это состязательность хозяйствующих субъектов, когда их самостоятельные действия эффективно ограничивают возможность каждого из них односторонне воздействовать на общие условия обращения товаров на соответствующем товарном рынке. В общепринятом смысле конкуренция - это соперничество, борьба за достижение больших выгод, преимуществ. Согласно большинству литературных источников, посвященных исследованию проблемы качества, рыночная конкуренция или конкуренция в самоорганизующейся экономической системе - это борьба производителя за ограниченный объем платежеспособного спроса со стороны потребителей, ведущаяся производителем на доступном ему сегменте рынка. Многие авторы считают основной целью повышения качества как движущей силой конкуренции - удовлетворение потребностей потребителя. Следует признать не совсем корректным разделение на две части основной задачи, которую решают производители продукции в процессе конкуренции: - удовлетворение потребностей потребителя; - борьбу за его свободные средства. Система качества пытается уменьшить вероятность риска путём исключения дополнительных неопределённостей, связанных с действиями конкурентов. Неадекватность реакции любой социальной системы выражается в её действиях, направленных на защиту своих возможностей и нейтрализацию действий конкурентов. Нейтрализация конкурентов повышает возможность системы управлять ситуацией на рынке [1]

\section{Результаты исследования и их обсулкение}

Повышение качества менеджмента можно обеспечить благодаря эффективно выстроенной системе внутреннего контроля, которая является частью внутренней контрольной среды.

Крупные государственные корпорации формируют систему внутреннего контроля, опираясь на мировую 
практику, и прежде всего систему COSO (The committee of sponsoring organizations of the treadway commission COSO). Такая система предполагает включение в эффективный внутренний контроль следующих составляющих:

- контрольные процедуры;

- оценка рисков;

- мониторинг и исправление ошибок;

- информация и коммуникации;

- среда контроля.

В российской практике внедряются отдельные элементы такой системы.

Подготовительный этап решения задач повышения качества менеджмента и его неотъемлемой составляющей - системы внутреннего контроля включает в себя исследование активов и обязательств, отраженных в учете, и подтверждение, что они действительно существуют. Следует изучить доходы и расходы предприятия, и подтвердить, что они полностью учтены в системе учета; факты хозяйственной жизни в течение проверяемого периода были разрешены соответствующими должностными лицами предприятия и не противоречили действующему законодательству; отраженные в учете факты хозяйственной практики относятся к проверяемому периоду.

Систему внутреннего контроля в наукоемком бизнесе можно представить как совокупность: надлежащей системы бухгалтерского учета; контрольной среды (предварительный контроль - до совершения факта хозяйственной жизни; текущий контроль - в процессе совершения факта хозяйственной жизни); отдельных средств контроля.

Важной составляющей является оценка контрольной среды, которая предполагает осведомленность и практические действия руководства экономического субъекта, направленные на установление и поддержание системы внутреннего контроля. В ходе ее построения необходимо проанализировать: основные принципы управления экономическим субъектом; организационную структуру экономического субъекта; распределение ответственности и полномочий; осуществление кадровой политики; соответствие хозяйственной деятельности экономического субъекта в целом требованиям действующего законодательства.

Построение системы внутреннего контроля как составляющей части системы менеджмента качества наукоемких предприятий предлагается выполнять с учетом стратегических установок, целей и задач, региональной неоднородности (разветвленности) и месторасположения ее обособленных подразделений, внешних условий функционирования организации, ее размеров, структура, масштабов и видов деятельности, ресурсного обе- спечения; уровня компетентности кадрового состава.

Эффективность системы внутреннего контроля предприятия должна достигаться за счет соблюдения за счет ряда основополагающих принципов:

- принцип ответственности (экономической, административной и дисциплинарной) каждого субъекта внутреннего контроля;

- принцип своевременного сообщения об отклонениях (при предварительном контроле несвоевременное сообщение о возможности возникновения отклонений не дает возможности своевременного реагирования);

- принцип интеграции (контроль рассматривается в корреляции с другими элементами в едином контуре процесса управления);

- принцип соответствия контролирующей и контролируемой систем (соответствие степени сложности системы внутреннего контроля степени сложности подконтрольной системы; наличие гибкой настройки звеньев системы внутреннего контроля на изменения соответственных звеньев системы объектов внутреннего контроля организации);

- принцип комплексности (охват объектов различного типа адекватным контролем);

- принцип согласованности пропускных способностей различных звеньев системы внутреннего контроля (обеспечение согласованной передачи данных в различных сопряженных звеньях системы внутреннего контроля, то есть оценка скорости обмена информацией между отделами);

- принцип разрешения и одобрения (обеспечение разрешения и одобрения всех финансово-хозяйственных операций ответственными официальными лицами в пределах их полномочий.).

Проверка качества менеджмента и системы внутреннего контроля должна рассматриваться через призму оценки и анализа: системы управления; системы обработки электронных данных; работы экономических служб; системы учета; системы контроля.

Каждая составляющая требует более детального рассмотрения для каждого экономического субъекта.

В ходе исследования системы управления на наукоемком предприятии Свердловской области было установлено, что организационная структура формализована и имеет обратную связь; имеются четкие границы полномочий и подотчетности с обратной связью; существует низкая текучесть управленческих кадров; в отчетном периоде на предприятии не действовала ревизионная комиссия.

Анализ и оценка системы обработки электрон- 
ных данных того же экономического субъекта показала, что в организации, осуществляющей бухгалтерский учет, имеется должность программиста (сетевого администратора); в течение года действовала неизменная система обработки данных.

Разработанная методика исследования системы учета позволила заключить:

- на предприятии разработана и утверждена учетная политика;

- для ведения учета используется лицензионная бухгалтерская автоматизированная программа;

- факты хозяйственной деятельности своевременно отражаются в бухгалтерском учете;

- изменения в учет после сдачи отчетности вносятся не на постоянной основе;

- соблюдаются установленный порядок подготовки и сроки сдачи бухгалтерской и налоговой отчетности.

Выполненный анализ системы контроля показал, что на предприятии установлены сроки сдачи внутренней отчетности (внутренних документов) в бухгалтерию; осуществлялась проверка правильности осуществления документооборота и наличия разрешительных записей руководящего персонала, регистрация входящих и исходящих документов; осуществлялось визирование первичных документов; не осуществлялось документальное оформление контрольных процедур; осуществлялось проведение плановых и внеплановых инвентаризаций имущества; проводились работа с персоналом, оперативные совещания, корпоративное обучение.

Поскольку возможно наличие риска системы внутреннего контроля, то было произведено тестирование системы внутреннего контроля с целью определения уровня надежности системы бухгалтерского учета и внутреннего контроля предприятия, а также их способности эффективно препятствовать появлению существенных искажений в бухгалтерской отчетности. Тестирование средств контроля включало:

- проверку документов, определяющих ведение бухгалтерского учета и формирование бухгалтерской отчетности;

- опросы и наблюдения для подтверждения функционирования системы внутреннего контроля в случаях, когда невозможно получить прямые документальные подтверждения;

- использование результатов других процедур для получения данных о работоспособности средств контроля.

Полученные результаты тестирования могут быть систематизированы в табличном виде (таб. 1).

Проанализировав данные исследования, специалист может сделать вывод, как оценить уровень риска системы внутреннего контроля. По нашему исследуемому экономическому субъекту (наукоемкому предприятию ракетно-космической отрасли) возможно оценить риск как средний.

С определенной степенью вероятности можно подтвердить, что система внутреннего контроля наукоемкого предприятия соответствует масштабам и характеру производственно-хозяйственной деятельности. При этом важно уточнить такую компоненту как конкурентоспособность.

Для оценки уровня конкурентоспособности необходима структуризация категории конкурентоспособности предприятия двумя способами с получением взаимосвязанных вариантов структуры.

Реакцию конкурентов на действия фирмы можно оценить и предупредить, используя предложенную М. Портером модель реакции конкурентов (рис.1):

Такой подход базируется на предположении о возможности ответных стратегических решений, которые вытекают из поведения потенциальных конкурентов. Следует исследовать технологический и маркетинговый вид инноваций аудит-процессов. При проведении аудита инновационной деятельности важнейшим представляется этап диагностики, который должен включать в себя оценку инновационного потенциала, среды функционирования и развития, инновационной активности и инновационной позиции предприятия

На основании выделенных свойств, с учетом классификации основных факторов внешней среды нами сформирована структура категории адаптивности предприятия. Выделены две основные составляющие: адаптивность в условиях колебания конъюнктуры (структурирована по основным направлениям возможных колебаний), и адаптивность в условиях вынужденного ухода с рынка (структурирована по основным факторам, определяющим возможность смены рода деятельности предприятия, либо прекращение существования предприятия). Следующий этап заключается в формировании конкурентных преимуществ, что возможно на основе устойчивого развития как фактора обеспечения экономической стабильности. Несмотря на обилие показателей, для оценки конкурентоспособности капитала предлагается показатель «Оценка прироста ценности». Расчет данного показателя, по мнению авторов, необходимо определять как соотношение финансового потока в виде суммы чистой прибыли и амортизации к стоимости активов минус заемные средства.

По исследуемым предприятиям получены следующие результаты. 
Таблица 1.

Предлагаемая матрица для оценки учетной информационной системы наукоемкого предприятия

\begin{tabular}{|c|c|c|c|c|c|c|c|}
\hline \multirow{2}{*}{$\begin{array}{c}\text { № } \\
\text { п/п }\end{array}$} & \multirow{2}{*}{ Факторы риска } & \multicolumn{6}{|c|}{ Классы риска } \\
\hline & & Высокий & Оценка & Средний & Оценка & Низкий & Оценка \\
\hline \multicolumn{8}{|c|}{ Система бухгалтерского учета и составление бухгалтерской отчетности } \\
\hline 1 & Учетная политика & --- & & --- & & $\begin{array}{l}\text { Утверждена и при- } \\
\text { меняется }\end{array}$ & \\
\hline 2 & $\begin{array}{l}\text { График документоо- } \\
\text { борота }\end{array}$ & --- & & --- & & $\begin{array}{l}\text { Утвержден и приме- } \\
\text { няется }\end{array}$ & \\
\hline 3 & $\begin{array}{l}\text { Неунифицированные } \\
\text { первичные документы }\end{array}$ & --- & & --- & & $\begin{array}{l}\text { Используются только } \\
\text { унифицированные } \\
\text { формы }\end{array}$ & \\
\hline 4 & $\begin{array}{l}\text { Архивирование до- } \\
\text { кументов }\end{array}$ & --- & & --- & & $\begin{array}{l}\text { Производится по видам } \\
\text { документов и годам }\end{array}$ & \\
\hline 5 & Автоматизация учета & --- & & --- & & $\begin{array}{l}\text { Полностью автомати- } \\
\text { зирован }\end{array}$ & \\
\hline 6 & Налоговый учет & --- & & --- & & $\begin{array}{l}\text { Ведется в полном } \\
\text { объеме }\end{array}$ & \\
\hline 7 & $\begin{array}{l}\text { Изменения в учет по- } \\
\text { сле сдачи отчетности }\end{array}$ & --- & & $\begin{array}{l}\text { Вносятся, но не- } \\
\text { значительны }\end{array}$ & & --- & \\
\hline 8 & $\begin{array}{l}\text { Должностные инструк- } \\
\text { ции работников }\end{array}$ & --- & & --- & & $\begin{array}{l}\text { Утверждены, соблю- } \\
\text { даются }\end{array}$ & \\
\hline 9 & $\begin{array}{l}\text { Руководитель и } \\
\text { главный бухгалтер за } \\
\text { проверяемый период }\end{array}$ & --- & & --- & & Не менялся & \\
\hline \multicolumn{8}{|c|}{ Процедуры контроля } \\
\hline \multicolumn{8}{|c|}{ Система независимых проверок } \\
\hline 10 & $\begin{array}{l}\text { Аудиторские проверки } \\
\text { за прошлые периоды }\end{array}$ & --- & & --- & & Проводятся ежегодно & \\
\hline \multicolumn{8}{|c|}{ Способы контроля и охраны } \\
\hline 11 & Инвентаризация & --- & & --- & & Проводится ежегодно & \\
\hline \multicolumn{8}{|c|}{ Документальное оформление } \\
\hline 12 & $\begin{array}{l}\text { Наличие и формирова- } \\
\text { ние документов }\end{array}$ & --- & & $\begin{array}{l}\text { Периодически } \\
\text { проводятся про- } \\
\text { верки } \\
\end{array}$ & & --- & \\
\hline \multicolumn{8}{|c|}{ Контрольная среда } \\
\hline \multicolumn{8}{|c|}{ Организационная структура и распределение ответственности и полномочий } \\
\hline 13 & $\begin{array}{l}\text { Разграничение } \\
\text { ответственности и } \\
\text { полномочий }\end{array}$ & --- & & --- & & Четкое разделение & \\
\hline 14 & \begin{tabular}{|l} 
Взаимодействие \\
между отделами (под- \\
разделениями)
\end{tabular} & --- & & Среднее & & --- & \\
\hline \multicolumn{8}{|c|}{ Кадровая политика } \\
\hline 15 & $\begin{array}{l}\text { Подбор сотрудников } \\
\text { финансовых отделов }\end{array}$ & --- & & $\begin{array}{l}\text { На основе со- } \\
\text { беседования }\end{array}$ & & --- & \\
\hline 16 & $\begin{array}{l}\text { Обучение сотрудников } \\
\text { финансовых отделов }\end{array}$ & --- & & $\begin{array}{l}\text { Имеет ограни- } \\
\text { ченный характер }\end{array}$ & & --- & \\
\hline \multicolumn{8}{|c|}{ Наличие службы внутреннего аудита } \\
\hline 17 & $\begin{array}{l}\text { Наличие внутреннего } \\
\text { аудита (ревизионной } \\
\text { комиссии) }\end{array}$ & --- & & $\begin{array}{l}\text { Ревизионная } \\
\text { комиссия из- } \\
\text { брана } \\
\end{array}$ & & --- & \\
\hline
\end{tabular}




\begin{tabular}{|c|c|c|}
\hline Цели конкурента & & Текущая стратегия \\
\hline & $\begin{array}{c}\text { Характер реакшии } \\
\text { конкурентов }\end{array}$ & \\
\hline $\begin{array}{c}\text { Самооценка занимаемой } \\
\text { позиции на рынке }\end{array}$ & & Маркетинговые возможности \\
\hline
\end{tabular}

Рис. 1. Модель реакции конкурентов

Таблица 2.

Расчетные показатели прироста ценности объектов

\begin{tabular}{|c|c|c|c|}
\hline \multirow{2}{*}{$\begin{array}{l}\text { Объекты } \\
\text { хозяйствования } \\
\text { Свердловской } \\
\text { области }\end{array}$} & \multicolumn{3}{|c|}{ Показатель «прирост ценности» } \\
\hline & 2017r. & 2018 г. & 2019 г. \\
\hline Объект А & 0,12 & 0,15 & 0,20 \\
\hline Объект В & 0,08 & 1,13 & 0,21 \\
\hline 0бъект С & 0,06 & 0,03 & 0,14 \\
\hline
\end{tabular}

На наш взгляд, в период трансформации экономики, показатель «прирост ценности» приобретает особую значимость, т. к. ценность и рост данного показателя имеют решающее значение для реализации экономических отношений между субъектами экономики. Кроме того, под приростом ценности целесообразно подразумевать оценку источника прироста за счет собственных средств. С позиции формирования стратегии развития предприятия предлагаемый показатель может быть использован для оценки инвестиционной привлекательности.

На уровень развития рыночных отношений влияет целый ряд факторов. Прежде всего - качество. Возможность свободного приобретения любых ресурсов, а также производства и реализации различных видов продукции в рамках установленного законодательства является одним из важнейших факторов развития рыночной экономики в демократическом обществе. Относительно высокий уровень свобод, имеющийся у любого индивидуума в отношении собственности, даёт ему возможность планировать свои действия, не считаясь с остальными членами социума и не ставя их в известность относительно своих дальнейших действий. Более того, непредсказуемость, закрытость информации о те- кущих и предстоящих действиях фирмы повышает вероятность ошибок её конкурентов при разработке контрмер и даёт возможность организации использовать свои преимущества более длительный период. Закрытость информации является одним из методов защиты собственных интересов любой системы контроля качества. Естественное желание системы защитить собственные интересы, не считаясь с интересами других членов социума, двояко действует на развитие социума в целом. С одной стороны, это желание является движущей силой в развитии социума, с другой - существенным тормозом. Совместить эти два противоположных явления достаточно сложно. Индивидуализм способствует формированию собственного, индивидуального подхода к решению какой-то конкретной задачи. Наличие нескольких вариантов решения одной задачи, разрабатываемых конкурентами, позволяет максимально использовать имеющиеся в обществе интеллектуальные ресурсы не только для разработки различных вариантов, но и для нахождения оптимального решения поставленной задачи.

\section{Выво $\Delta ы$}

Система менеджмента качества на промышленных и в том числе наукоемких предприятиях должна непрерывно совершенствоваться. Разработанные методические рекомендации по оценке и контролю системы позволяют повысить эффективность управления и результативность деятельности. Современная ситуация, подтверждающая высокую степень антропогенной нагрузки, может быть решена на основе учета инновационной составляющей [3-6, 8]. В контексте данного положения исследованию подлежат экономические аспекты в данной области, которые выражаются в проектировании мероприятий в области логистических цепочек в системе контроля качества.

\section{ЛИТЕРАТУРА}

1. Бутко, Г.П. Повышение конкурентоспособности как фактор обеспечения экономической безопасности: монография / Г.П. Бутко, Л.А. Перепелкина, 0.А. Шурмина; под ред. проф. Г.П. Бутко. - Екатеринбург: УглтУ, 2019. - 142 с

2. Гуманюк, Е.С. Эффективность деятельности бизнес-процессов на основе управления качеством на примере ракетно-космической промышленности (РКП) [Текст] / Е.С. Гуманюк // Экономика и предпринимательство. - 2017. - № 9-3 (86). - С. 1223-1226. - 0,34 п.л.

3. Концепция эффективного предпринимательства в сфере новых решений, проектов и гипотез. Шаркова А.В., Килячков Н.А., Белобрагин В.В. и др. Коллективная монография. Москва, 2019 (2-е издания) 
4. Меньшикова М.А. Формирование инструментов и механизмов современной системы оперативного управления лесопромышленного производства. Вестник Московского государственного университета леса- Лесной вестник. 2011. №1. с.125-128

5. Тенденции развития цифровых технологий [Электронный ресурс]. URL: http://mniap.rf/analytics/Trendy-cifrovyh-tehnologij-v-APK/ (по состоянию на 05/11/2019).

6. Основы управления инновационной деятельностью предприятия: учебное пособие / Г.П. Бутко, Л.А. Раменская, Я.В. Савченко. Ек.: УрФУ, 2013. 142 с.

7. Инновационная деятельность корпорации. Монография. / Г.П. Бутко Ек. УрФУ. 2013. 182 с.

8. Сысоева Л. Формирование инвестиционной и инновационной деятельности - основа формирования бюджета хозяйствующего субъекта. // Инновации и инвестиции. 2018. №3.

9. Бутко Г.П., Поротников П.А., Велиева О.В. Управление природоохранной деятельностью на основе кластера инновационного типа // Известия УрГЭу. 2010. №2 (28). С. 162-168.

10. Меньшикова М.А. Современный аудит. М.: МГУЛ. 2009. 222с.

11. Ефимов В.А. Трансформационная экономика. СПб. Финансы и статистика. 2020. 232 с.

12. Bykovskiy M.A., Tikhomirov E.A. Modelling decision-making process when choosing an import multifunctional logging equipment for the conditions of the Russian Federation // Pushing the Boundaries with Research and Innovation in Forest Engineering. 2011. C. 1-6.

13. Mindlin Y.B., Stolyarov N.S., Novikova N.V., Smolentsev V.M., Tikhomirov E.A. Evaluation of competitive advantages of regional economic clusters // Espacios. 2018. T. 39. № 31.

14. Mindlin Y.B., Tikhomirov E.A., Kozhuhov N.I., Nazarenko E.B. The mechanism of introduction of clusters in the Russian Federation // Humanities and Social Sciences Reviews. 2019. T. 7. № 4. C. 767-772.

15. Tikhomirow E., Bykovskiy M. The current state and approaches to evaluation of investment attractiveness of timber industry of the Russian Federation // Forest engineering Making a positive contribution. Abstracts and Proceedings of the 48th Formec Symposium 2015. 2015. C. 395-400.

( Бутко Галина Павловна (gpbutko@mail.ru), Меньшикова Маргарита Аркадьевна (Ivn-3@yandex.ru),

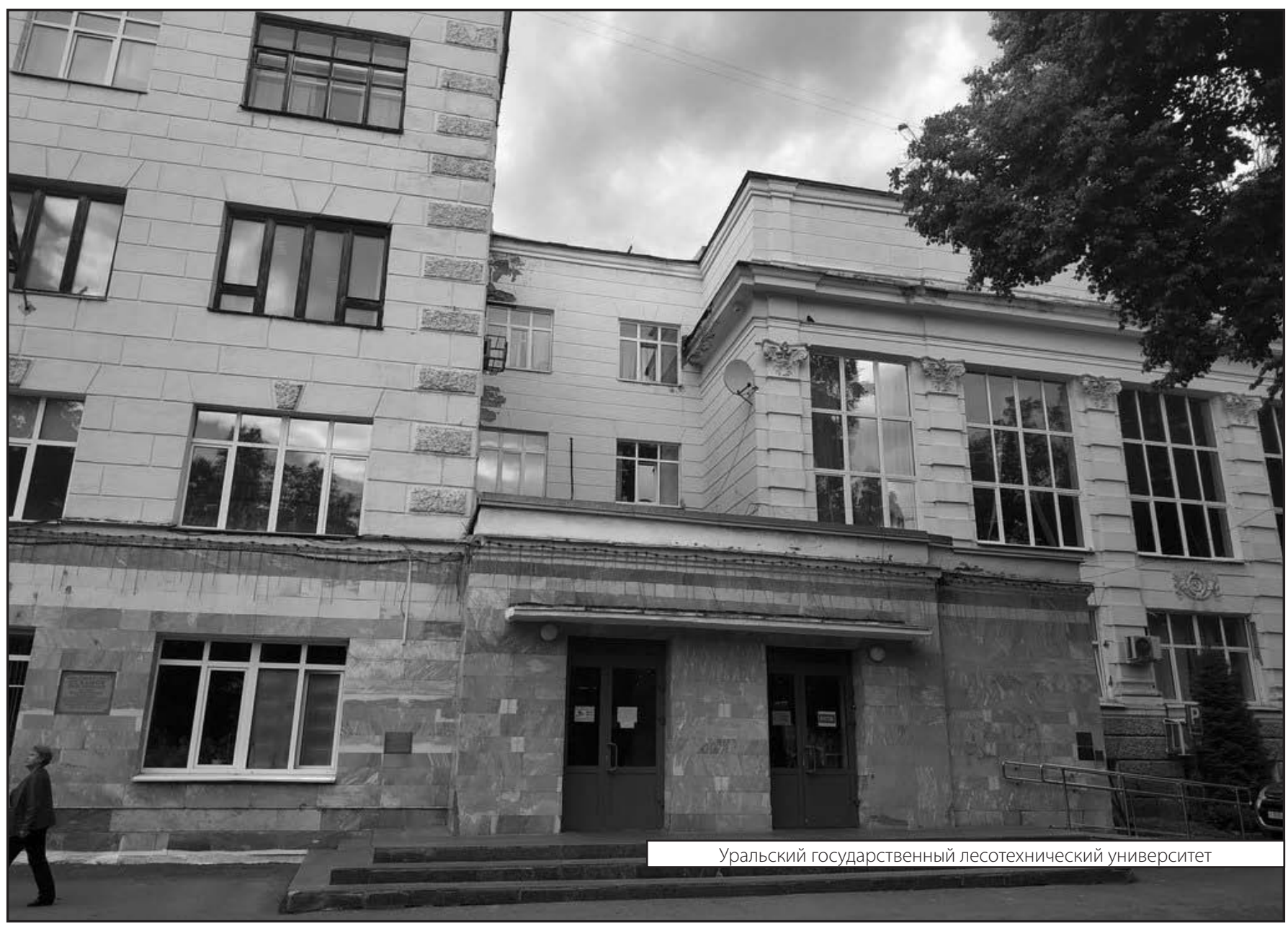

